\title{
DOENÇA MENTAL E CINEMA: UMA ANÁLISE PSICOSSOCIAL
}

\author{
Camila Borsato Rocchi (Psicologia - UEL) \\ Profa. Sonia Regina Vargas Mansano (Orientadora)
}

\section{RESUMO}

O cinema pode ser considerado uma invenção recente e de grande impacto psicossocial à medida que demonstrou ser um meio para vinculação de informações, sensibilização e denúncia. Amparado em tecnologias diversas, a sétima arte concretizouse como uma linguagem ao mesmo tempo única (por sua maneira de atuar) e universal (acessível aos diferentes habitantes do globo). Assim, nota-se seu grande impacto no contexto urbano. Quer pela via do entretenimento, da disseminação de conhecimento ou da denúncia, o cinema afeta públicos distintos. Especialmente no chamado cinema offhollywood encontram-se tematizadas diversas problemáticas psicossociais, sendo que o foco deste estudo consiste em analisar especificamente como a questão das doenças mentais é nele abordada. Com isso, busca-se elencar e analisar as maneiras como o cinema difunde informações, valores, componentes subjetivos e sensibilidades acerca da doença mental, ressaltando o imaginário social. A pesquisa debruçou-se nos seguintes aspectos: imagens veiculadas à doença mental, abordagens dos tratamentos, referência a manuais como DSM ou CID e os modos de vida das pessoas diagnosticadas como doentes mentais em contexto urbano. Como resultado parcial, pode-se dizer que a abordagem do tema pelo cinema atual é fortemente marcada pela perspectiva nosográfica e pela indústria farmacêutica, em especial na produção do cinema hollywoodiano.

Palavras-chave: cinema, psicologia social, doença mental

\section{INTRODUÇÃO}

Apesar da desmedida abundância de informações disponíveis na internet, sendo muitas delas, por vezes, contraditórias ou falsas, nunca foi tão facilitado o acesso à informação em diversas áreas e partes do mundo por um amplo número de indivíduos localizados em classes sociais e faixas etárias distintas. No entanto, vale frisar que a "sociedade é que dá forma à tecnologia de acordo com as necessidades, valores e interesses das pessoas que utilizam as tecnologias" (CARDOSO, 2005, p. 17). Dentre as formas possíveis de transmissão de mensagens, destaca-se, aqui, uma rede que se iniciou dando preferência à comunicação visual, incorporando, depois, a sonora, e que se consagrou, posteriormente, conquistando a posição de "Sétima Arte": o cinema.

Enquanto manifestação artística, o cinema é permeado constantemente por questões de ordem subjetiva: afinal, trata-se de uma arte cujo processo de criação é complexo, exigindo, além da sensibilidade, uma série de conhecimentos e preparos técnicos. Da mesma forma, pode-se dizer que o cinema admitiu não somente uma, mas diversas atribuições políticas em nossa sociedade como, por exemplo, o caráter documental, a denúncia e a crítica social.

Pode-se dizer que, em pleno século XXI, tem-se um cinema- com sua terminologia em seu sentido mais amplo- já não tão monopolizado nas produções de 


\section{SEMINÁRIO DE PESQUISA EM CIÊNCIAS HUMANAS - SEPECH \\ Humanidades, Estado e desafios didático-científicos \\ Londrina, 27 a 29 de julho de 2016}

Hollywood. Além disso, ele conta com um acúmulo de experiência (diga-se de passagem, com mais de 100 anos) tanto em seu aspecto técnico e tecnológico quanto artístico e conceitual. Esta dimensão múltipla da produção cinematográfica permite que a Psicologia Social aproxime-se de temas que atravessem essa produção artística e produz efeitos na população urbana, seja na condição de entretenimento, seja como veículo de denúncia. Assim, propõe-se neste estudo uma análise sobre como as questões referentes às doenças mentais e seus efeitos subjetivos são retratados no cinema. Para tanto, o estudo percorre dois momentos: Primeiro, é realizada uma breve retrospectiva histórica sobre a criação e consolidação do cinema como uma arte. Em seguida, discute-se em que medida o cinema retrata a doença mental, abordando dos momentos históricos distintos: entre os anos de 1930 e 1935, época da consolidação dessa arte através da ascensão do cinema Hollywoodiano. E os anos de 2010 a 2015, que envolve o contemporâneo.

\section{CINEMA: ALGUMAS CONSIDERAÇÕES HISTÓRICAS}

Marie-Georges-Jean-Méliès é considerado um dos maiores nomes representantes da emancipação do cinema. Martin (2003) atribui à Méliès o lugar de criador da sétima arte pelo fato de o mesmo prosseguir seus ilusionismos a partir do cinema: para ele, Méliès foi capaz de criar com originalidade, inventando o "espetáculo cinematográfico" (MARTIN, 2003, p. 15). O poder de persuasão dos filmes iniciou-se cedo. Exemplo disso pode ser encontrado no filme dos irmãos Lumiére (outro polo original do cinema) intitulado "Chegada de um trem à estação" - película que retrata cenas simples e cotidianas - que gerou intrigas e debates. Sobre isso, relata Câmara (2013, p. 8): "Conta a lenda que a "chegada do trem" assustou a plateia: (...) acreditou-se que o trem atravessaria a tela, invadiria a sala e atropelaria os espectadores. Curiosamente, o público não percebeu que as imagens não tinham cor, nem som, nem relevo".

A capacidade de captar movimentos e reproduzí-los atraiu a admiração do público. Percebe-se que o cinema não havia conquistado apenas o caráter documental (uma vez que era capaz de realizar cópias fiéis da realidade), mas também era dotado de um caráter teatral - sendo possível perceber a capacidade dos diretores para manipulação de imagens e direcionamento de enfoque para quaisquer conteúdos. Assim, o cinema consolidou-se como uma ilusão da reprodução do movimento da vida. Trata-se de uma ilusão, pois um filme nada mais é do que "uma série de fotogramas, imagens fixas, que ficam dispostas em sequência e que, passando de maneira ritmada, dão origem a uma imagem aumentada que se move - a qual visualizamos em certo quadro" (CHRISTOFOLETTI, 2013, p.20). Assim, não existe, de fato, o movimento, mas a ilusão do mesmo. E foi a partir desta ilusão que o cinema ganhou abertura para misturar a realidade e a fantasia, possibilitando às pessoas que assistiam aos filmes se desconectar da realidade em que se encontravam e participar da nova realidade fantasiosa forjada que o cinema se propunha a exibir.

Aqui, a fantasia pode ser compreendida não somente como efeitos especiais criados com a ajuda de tecnologias, mas enquanto forma de simular, na sala de cinema (que envolve um ambiente escuro e evita outros estímulos que não os visuais e sonoros, concentrando a atenção do espectador no que está sendo projetado), uma nova realidade: a do filme projetado. Este ambiente protegido pode explicar o porquê de as pessoas 


\section{SEMINÁRIO DE PESQUISA EM CIÊNCIAS HUMANAS - SEPECH \\ Humanidades, Estado e desafios didático-científicos \\ Londrina, 27 a 29 de julho de 2016}

conseguirem se sentir "tocadas" pelo enredo; afinal, elas conseguem participar, mesmo como testemunhas oculares afetadas, daquele momento e daquele conteúdo que é simulado pelo filme.

Todos estes recursos e técnicas descobertos durante os primórdios do nascente cinema colaboraram para que este não apenas utilizasse da linguagem para se expressar, mas que se estabelecesse enquanto uma nova linguagem, que se faz ao mesmo tempo singular e conhecida universalmente. Martin (2003) chama esta passagem de reconhecimento do cinema de cinema-linguagem para cinema-ser, na qual há uma revolução, segundo ele, da linguagem. E complementa:

Mas o que distingue o cinema de todos os outros meios de expressão culturais é o poder excepcional que vem do fato de sua linguagem funcionar a partir da reprodução fotográfica da realidade.[...] Tal originalidade advém essencialmente de sua onipotência figurativa e evocadora, de sua capacidade única e infinita de mostrar o invisível tão bem quanto o visível, de visualizar o pensamento juntamente com o vivido, de lograr a compenetração do sonho e do real, do impulso imaginativo e da prova documental, de ressuscitar o passado e atualizar o futuro, de conferir a uma imagem fugaz mais pregnância persuasiva do que o espetáculo do cotidiano é capaz de oferecer (MARTIN, 2003, p.18$19)$.

Estes fatos abrem espaço para questionar e, talvez, compreender melhor os motivos para o cinema ter evoluído tanto em um reduzido contexto cinematográfico profissional e elitista quanto em popularidade, tornando-se ao mesmo tempo um objeto glamourizado e marginalizado. Nesta dualidade (glamour e marginalidade), tem-se, por um lado, uma indústria cinematográfica que demanda alto gasto financeiro (e, portanto, restringe a arte de "fazer cinema" a poucos indivíduos); enquanto, por outro lado, tem-se a necessidade de que esta arte seja comercializada e difundida ao máximo possível entre um público diversificado, para que os gastos sejam cobertos. Assim, o cinema, apesar de elitista em sua criação, firma-se enquanto uma arte de consumo em massa.

A massa é atingida, majoritariamente, pela fundamental característica do cinema de ter expressar ideias gerais e abstratas, tornando possível suscitar no espectador sentimentos de realidade bastante fortes. Esta diferenciação da linguagem cinematográfica é explicada, por Martin (2003), em três pontos:

primeiro, porque toda imagem é mais ou menos simbólica[...]. Em segundo lugar, a imagem fílmica está sempre no presente [...]: o pretérito perfeito, o imperfeito, eventualmente o futuro, são apenas o produto de nosso julgamento colocado diante de certos meios de expressão cinematográficos cuja significação aprendemos a ler (MARTIN, 2003, p.24-25).

É possível compreender este segundo ponto empiricamente com o exemplo de um espectador que chega à sala de cinema no meio de um filme e se depara com uma cena referente ao passado: neste caso, ele provavelmente verá a cena como no presente, uma vez que a referência de passado é transmitida pelo próprio filme; assim, o filme nada mais é que uma história eternizada no presente. 


\section{SEMINÁRIO DE PESQUISA EM CIÊNCIAS HUMANAS - SEPECH \\ Humanidades, Estado e desafios didático-científicos \\ Londrina, 27 a 29 de julho de 2016}

O último ponto evidenciado por Martin (2003) faz-se consequência do segundo. Uma vez que os conteúdos, incluindo lembranças e sonhos vividos pelas pessoas também se passam no presente, é possível estabelecer uma ponte entre o cinema e o irreal, o imaginário.

Isso permite compreender com que facilidade o cinema pode exprimir o sonho, e sobretudo que prodigioso alimento o filme constitui para o sonho e, mais ainda, para o devaneio acordado: é bem verdade que os "intoxicados" de cinema podem acabar não distinguindo mais, em sua memória, as imagens fílmicas das lembranças de percepção real, tamanha a identidade estrutural desses dois fenômenos psíquicos (MARTIN, 2003, p.25).

Estes três pontos elencados ajudam a compreender a partir de quais recursos básicos o cinema desenvolveu condições para assumir-se enquanto autônomo, de linguagem exclusiva e universal de seu cenário, e capaz de "tocar" às pessoas, independente de sua faixa etária, assim como sua localização em classes sociais e econômicas. Vale ressaltar que esta condição para assumir caráter de massas e grande impacto foi principalmente conquistada a partir de um contexto mundial político favorável à eclosão desta sétima arte. Garcia (2011) relata que um dos fatores mais fortes foi o impacto gerado pela Primeira Guerra Mundial (1914-1919), que abriu espaço para que a produção americana ganhasse força e mercado.

A tão famosa Hollywood, localizada na cidade de Los Angeles, encontrou, nesta época, espaço para se desenvolver. Nesta década de 1910, estúdios de cinema foram majoritariamente criados, o que constitui marco determinante para a fortificação da indústria aplicada ao cenário cinematográfico.

Apesar da dominância do cinema do tipo Hollywoodiano no mercado, é possível reconhecer a emergência de novas produções de baixo orçamento, mas de grande criatividade e aceitação de alguns públicos. No entanto, em decorrência da crise de Hollywood no final dos anos 1960 - ocorrida em função de uma saturação estética e mercadológica dos blockbusters - têm-se os novos cinemas emergentes. Estas produções off-hollywood, isto é, realizadas fora da capital mundial do cinema e também atualmente conhecidas como cinema independente, têm aceitado diversas nomenclaturas exatamente pelo fato de ainda não estarem consolidadas diante do cenário cinematográfico atual. Englobam, portanto, "cinema independente, cinema de garagem, cinema amador, cinema jovem. Tais termos procuram agrupá-los ora através de suas características estéticas, ora por suas estruturas de produção" (PINTO, 2013, p.5).

\section{DELINEANDO UMA TRAJETÓRIA METODOLÓGICA}

Como já abordado anteriormente, na história do cinema, a evolução tecnológica possibilitou a vários diretores, a partir dos filmes, trazer a problemática da doença mental para o espectador, abordando-a em diversas perspectivas. Uma vez que o cinema se faz presente na história da humanidade desde o final do século XIX e que a cada momento ele se mostra acessível a diferentes públicos, é fato que o mesmo exerce determinadas funções sociais e políticas. Cabe ressaltar, entretanto, que apesar de retratarem diversas 


\section{SEMINÁRIO DE PESQUISA EM CIÊNCIAS HUMANAS - SEPECH \\ Humanidades, Estado e desafios didático-científicos \\ Londrina, 27 a 29 de julho de 2016}

situações da vida cotidiana, as produções cinematográficas também seguem uma linha de mercado tanto para agradar ao público, pela via do entretenimento, quanto para gerar lucro.

Diante desse cenário multifacetado, foram definidos dois critérios para definição da unidade a ser analisada, identificando como a doença mental se faz presente e representada nos filmes produzidos. Primeiro, foi definido o momento histórico para proceder a análise. As épocas escolhidas para tal discussão encontram-se no ápice Hollywoodiano, na década de 30 (também conhecido por "Era de Ouro"), e no atual cenário fílmico, que engloba suas produções tanto independentes quando de Hollywood. Esta escolha de épocas distintas - com o intervalo de 80 anos - tem o intuito de analisar como que frequência e com qual nomenclatura o tema foi abordado. Assim, buscou-se descrever e analisar dois momentos históricos que se valem de visões e perspectivas distintas em relação à maneira de definir e caracterizar a doença mental.

Em segundo lugar, definiu-se o gênero a ser analisado. Como já elucidado anteriormente, o cinema encontra ampla referência no teatro que contribuiu para seu desenvolvimento e consolidação. Como grande representante da arte teatral tem-se o drama, caracterizado como "o conjunto do gênero teatral, por oposição ao lirismo e à epopéia" (AUMONT, 2003, p.87). A presente pesquisa restringir-se-á a este gênero para delimitar as incidências de tematização da doença mental no cinema.

Os dados apresentados na sequência foram retirados do site Internet Movie Database (IMDB), que representa a maior base de dados online de filmes, TV e informações de celebridades. Eles foram coletados entre os meses de abril e maio do ano corrente.

\section{INTERFACES ENTRE O CINEMA E DOENÇA MENTAL}

De acordo com o referido site, no período de 1930-1935 foram lançados 11.311 filmes, incluindo todos os gêneros considerados pelo site. Destes, $26 \%$ destinavam-se ao gênero drama. Especificamente no gênero drama, foi possível encontrar, dentre os 3007 filmes catalogados, apenas 26 referências à doença mental.

Para chegar a esse número referente à abordagem da temática, foram buscadas as seguintes palavras-chave: loucura (madness); insanidade (insanity); doença mental (mental illness) e transtorno mental (mental disorder). O quadro abaixo ilustra a porcentagem do gênero drama em relação aos demais gêneros, bem como, dentro do drama, o percentual da temática loucura. 


\section{SEMINÁRIO DE PESQUISA EM CIÊNCIAS HUMANAS - SEPECH \\ Humanidades, Estado e desafios didático-científicos \\ Londrina, 27 a 29 de julho de 2016}

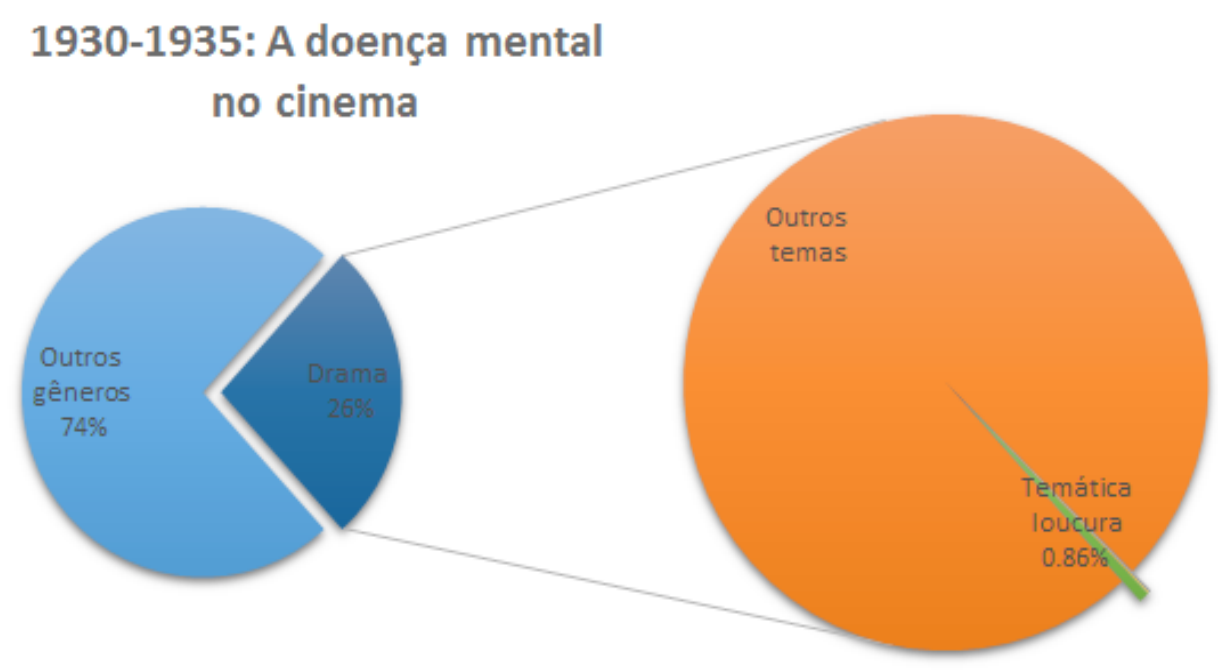

Quadro 1: A doença mental no cinema entre 1930 - 1935

Fonte: Elaborado pela autora com base no site IMDB

Já no período de 2010 a 2015, tem-se listado um total de 120.594 longasmetragens lançados, dos quais 32.473 enquadram-se no gênero drama. Deste modo, no quadro 2, percebe-se que o gênero drama domina $27 \%$ do total de filmes lançados nesta época.

\section{0-2015: A doença mental}

\section{no cinema}

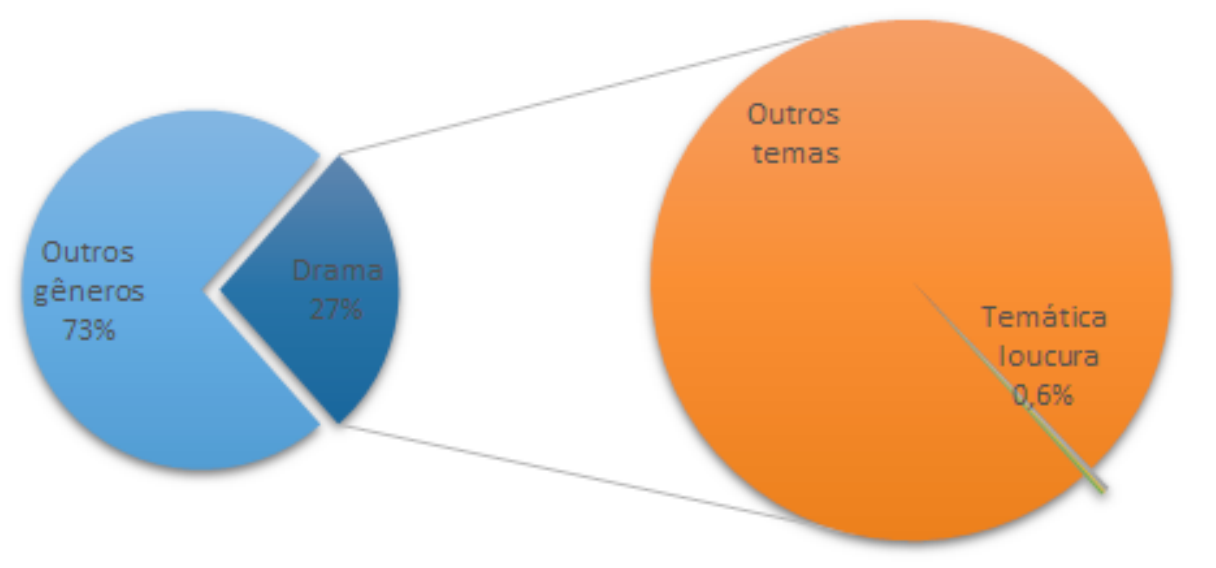

Quadro 2: A doença mental no cinema entre 2010 a 2015

Fonte: Elaborado pela autora com base no site IMDB

Logo de início, é perceptível a pequena diferença percentual da incidência do tema doença mental nos dois períodos definidos para análise. Entre 1930-1935, 0,86\% dos filmes do gênero drama abordaram a temática loucura, enquanto $0,6 \%$ dos filmes de 2010-2015 discorriam acerca do mesmo conteúdo. Aqui, nota-se que não houve uma diferença significativa entre a porcentagem de produções que tratam da loucura. 


\section{SEMINÁRIO DE PESQUISA EM CIÊNCIAS HUMANAS - SEPECH \\ Humanidades, Estado e desafios didático-científicos \\ Londrina, 27 a 29 de julho de 2016}

No entanto, comparando o início das décadas de 1930 à de 2010, nota-se que a gama de filmes produzidos, dentro do gênero drama, de quaisquer temáticas, sofreram um aumento significativo em quantidade, correspondente a pouco mais de $1000 \%$. Isso pode ser compreendido como a relevância que o tema ganhou para o contexto urbano, sendo retratado nos filmes. Apesar de a porcentagem do tema permanecer pequena, a quantidade bruta de filmes que abordaram esta questão aumentou em quase oito vezes. Assim, se em 1930-1935 foram encontrados 26 filmes relacionados, de alguma forma, à doença mental, em 2010-2015, 195 filmes tematizam esta problemática. A abertura para se discutir e retratar o tema nas telas do cinema, fazendo diálogos com áreas distintas de conhecimento, é perceptível e aponta para uma problemática que atravessa o contexto atual urbano.

A tabela 3, apresentada abaixo, compara a incidência dos termos são utilizados em cada uma das épocas pesquisadas. Nela é possível notar que, no período de 19301935, o termo "transtorno mental" (mental disorder) não aparece nenhuma vez durante a pesquisa, enquanto "insanidade" (insanity) aparece com maior frequência, apresentando $71,1 \%$ de ocorrência. A expressão "doença mental" (mental illness) aparece em 19,2\% das vezes; a loucura (madness), apenas $7,7 \%$ das vezes. Chama a atenção a incidência significativa do termo "transtorno mental" (mental disorder), que não apareceu nenhuma vez como referência aos filmes no primeiro período investigado.

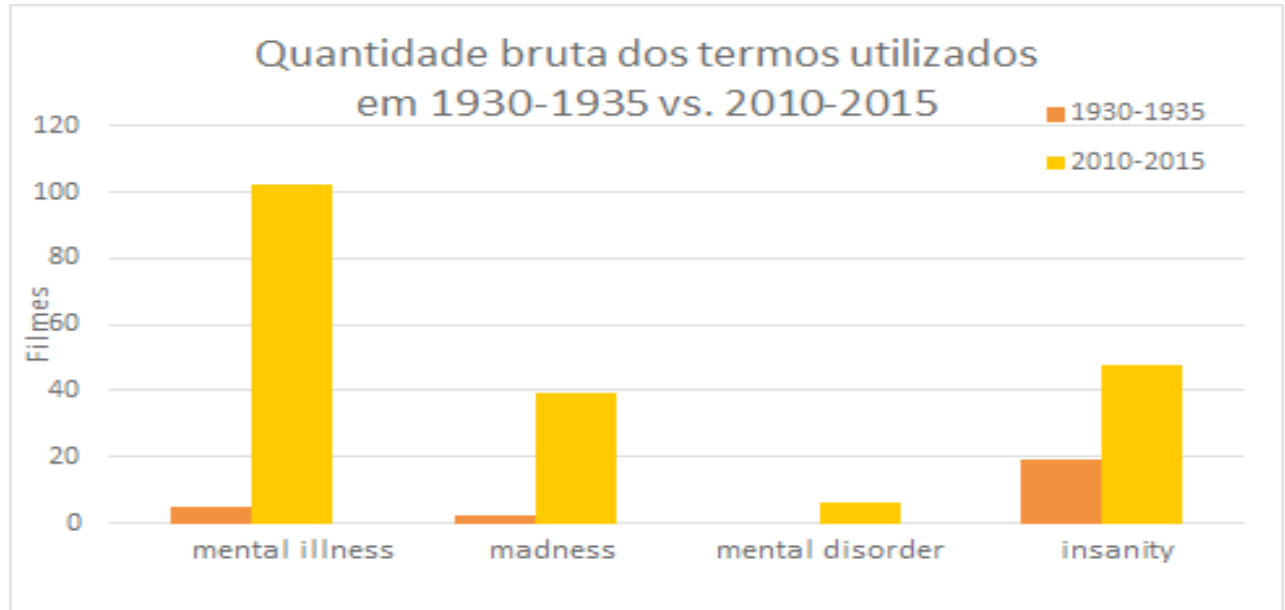

Tabela 3: Quantidade bruta dos termos utilizados em 1930-1935 vs. 2010-2015

Fonte: Elaborado pela autora com base no site IMDB

Por outro lado, o termo "insanidade" (insanity) apresenta uma ocorrência bem menor, referente a 24,6\%; enquanto "loucura" (madness) se enquadra nos 20\% de ocorrência e, a "doença mental" (mental illness), 52,3\% dos casos. O termo doença mental ultrapassa o termo "insanidade" no que se refere à nomenclatura mais utilizada na busca de filmes que se relacionem à temática.

Cabe ressaltar que a utilização do termo de maior incidência (insanity) em 19301935 já se fazia presente na história do século XX. Goffman comenta:

Por exemplo, quando o paciente mental está no sanatório, e quando se encontra com membros adultos de sua família ele é tratado com tato, como se fosse sadio quando, na realidade, há dúvidas sobre isso, mesmo 


\section{SEMINÁRIO DE PESQUISA EM CIÊNCIAS HUMANAS - SEPECH \\ Humanidades, Estado e desafios didático-científicos \\ Londrina, 27 a 29 de julho de 2016}

que não de sua parte ou, então, ele é tratado como insano quando sabe que isso não é justo (GOFFMAN, 1963/2004, p.38).

Goffman (1963/2004) ilustra bem esta relação, apontando o estigma social em torno de quem era considerado "insano" que sofria, por parte dos ditos normais ou saudáveis, uma série de reprimendas e desqualificações. Assim como as mudanças sociais ocorrem nos contextos urbanos, a linguagem utilizada para denominar e descrever a doença mental também se modifica, já que é viva e produto das práticas sociais. Assim, as nomenclaturas utilizadas também são modificadas, ganhando, por vezes, novos significados, ou mesmo entrando em desuso, fato que abre para utilização de novos termos.

$\mathrm{Na}$ análise da tabela 3 observa-se, de início, uma mudança significativa de termos: em contraposição a 1930-1935, onde não foi mencionado vez algum, o termo "transtorno mental" (mental disorder), o mesmo aparece, em 2010-2015, em 3,1\% dos casos de filmes. Por mais que a porcentagem ainda se mantenha baixa, é preciso atentar-se para o fato de que um termo ausente na primeira fração histórica estudada, aparece mais recentemente em 3,1\% dos casos, correspondente a 6 filmes. Este dado pode apontar que a incidência do termo no cinema acompanha as relações urbanas e concepções que se têm acerca da doença mental na contemporaneidade.

No que tange às áreas de conhecimento representadas pela psiquiatria e psicologia, a definição de doença mental não poderia se fazer estática. $\mathrm{Na}$ sua história de produção de conhecimento, a instituição medico-psiquiátrica elaborou manuais classificatórios como o CID 10 (Classificação Internacional de Doenças e Problemas Relacionados à Saúde) e o DSM (Manual Diagnóstico e Estatístico de Transtornos Mentais) para descrever as patologias e colocar à disposição dos profissionais informações de referência para elaboração de diagnósticos. Trata-se de manuais que são frequentemente revisados, sendo acrescentadas novas categorias de transtornos mentais a cada edição. Do DSM-I ao DSM-IV, foram adicionadas 268 novas categorias reconhecidas (BURKLE, 2009). Atualmente, o DSM encontra-se em sua quinta versão, lançada em 2013. Vale ressaltar que o termo "transtorno mental", de fato, foi fixado nos discursos médicos-psiquiátricos- com maior incidência em instrumentos como o CID-10 e DSM- tornando-o comum e trazendo uma nova ótica sobre a perspectiva da loucura.

O uso mais recente do termo "transtorno", de certo modo, também requer uma análise. Por transtorno, compreende-se, de acordo com Houaiss $(2009$, p. 1870) "1 ato ou efeito de transtornar 2 situação que causa incômodo a outrem; contratempo (...) 3situação imprevista ou desfavorável; contrariedade, decepção (...) qualquer perturbação da saúde. Já no DSM-5, é possível delimitar o termo transtorno como uma perturbação que "causa sofrimento clinicamente significativo ou prejuízo no funcionamento social, profissional, ou em outras áreas importantes da vida do indivíduo" (AMERICAN PSYCHIATRIC ASSOCIATION, 2014, p. 21). Também é encontrada a definição de transtorno mental, este descrito como:

uma síndrome caracterizada por perturbação clinicamente significativa na cognição, na regulação emocional ou no comportamento de um indivíduo que reflete uma disfunção nos processos psicológicos, biológicos ou de desenvolvimento subjacentes ao funcionamento mental (AMERICAN PSYCHIATRIC ASSOCIATION, 2014, p. 20). 


\section{SEMINÁRIO DE PESQUISA EM CIÊNCIAS HUMANAS - SEPECH \\ Humanidades, Estado e desafios didático-científicos \\ Londrina, 27 a 29 de julho de 2016}

Pode-se notar que a palavra transtorno não totaliza o sujeito em uma característica doente, mas aponta para uma situação que pode ser cotidiana e que coexiste em relação a outras dimensões da existência. Assim, apresentar um transtorno, por mais grave que este possa ser, assume contorno diferentes de uma doença mental mais fixa e duradoura, possibilitando, assim um maior número de sujeitos identificados. No espaço urbano contemporâneo, os transtornos são diluídos em uma população mais ampla, sem com isso necessariamente promover processos de exclusão e desqualificação.

\section{CONSIDERAÇÕES FINAIS}

Os dados levantados sobre a incidência do tema doença mental nos cinemas trazem aos estudos da Psicologia Social não somente estatísticas, mas também a relevância da linguagem e do discurso de cada época analisada. Em nosso entendimento, a produção discursiva colabora para circunscrever e definir visões de mundo e de sujeito que são amplamente compartilhadas.

Sendo assim, nota-se que o cinema acompanha as mutações das relações urbanas, evidenciando que as cidades implicam um contexto de multiplicidade e produção de modos de vida. Assim, a cada novo filme lançado, com suas particularidades mercadológicas, mas também de retrato social, novas imagens e discursos são colocados em cena, evidenciando a importância social dessa sétima arte.

\section{REFERÊNCIAS}

AMERICAN PSYCHIATRIC ASSOCIATION et al. Manual diagnóstico e Estatístico de Transtornos Mentais-: DSM-5. Artmed Editora, 2014.

AUMONT, J. MARIE, M. Dicionário teórico e crítico de cinema. Tradução Eloisa Araújo Ribeiro.- Campinas, SP: Papirus, 2003.

BURKLE, T.D.S. Uma reflexão crítica sobre as edições do Manual de Diagnóstico e Estatística das Perturbações Mentais - DSM. Dissertação de Mestrado, Instituto de Estudos em Saúde Coletiva, Universidade Federal do Rio de Janeiro, Rio de Janeiro, 2009.

CARDOSO, G. CASTEllS, M. A Sociedade em Rede: Do Conhecimento à Acção Política. Lisboa: Imprensa Nacional - Casa da Moeda: 2005

CHRISTOFOLETTI, R. Ensaio-fílmico: cinema, loucura e resistência. São Paulo: Cultura Acadêmica, 2013.

FABRIS, E. H. Cinema e educação: um caminho metodológico. Revista Educação \& Realidade, 2008, v.33, n.1. p.117-134

IMDB. Disponível em: www.imdb.com. Acesso em: 05 maio 2016 


\section{SEMINÁRIO DE PESQUISA EM CIÊNCIAS HUMANAS - SEPECH \\ Humanidades, Estado e desafios didático-científicos \\ Londrina, 27 a 29 de julho de 2016}

GARCIA, A. C. A fantástica fábrica de filmes: como Hollywood se tornou a capital mundial do cinema. Rio de Janeiro: Ed. Senac Rio, 2011.

GOFFMAN, E. Estigma: Notas sobre a Manipulação da Identidade Deteriorada. Rio de Janeiro, Zahar Editores, 1978 (1963).

MARTIN, M. A linguagem cinematográfica. São Paulo: Editora Brasiliense, 2003.

PINTO, J. 'The Mumblecore Kids': a nova geração do cinema independente. Trabalho de Conclusão de Curso (Graduação em Comunicação Social - Cinema) Universidade Federal Fluminense, 2013. 